\title{
Games And Students: Perceptions And Evidence From A DUT Case Study
}

Jason Stratton Davis, Durban University of Technology, ML Sultan Campus, South Africa

\begin{abstract}
The poor performance of first year economics students across higher education institutions is a well-established phenomenon (Parker, 2006). The traditional response has been to analyse this poor performance using a production function where factors are identified and their influence measured. The problem, however, may not be solved entirely by looking at the factors, but at the production function i.e. the relationship between learning and the mode of delivery.

This article seeks to challenge the traditional mode of lecture-based learning by introducing economic games into the formal tuition programme. The evidence collected during research indicates positive results in terms of students' perceptions and performance.
\end{abstract}

Keywords: Education; Games; Students; Learning; Survey

\section{BACKGROUND AND RATIONALE FOR STUDY}

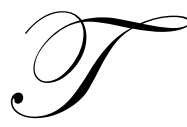

problems.

he Durban University of Technology (DUT) is the context within which my lecturing of first year economics is undertaken. This course is compulsory for marketing, management and accounting qualifications as it aims to introduce and enable students to become aware of central economic

The overall performance of students in the first year economics course at DUT has been poor, but this phenomenon is not particular to the institution. And at present economics is seen by students as problematic, abstract and theoretical. The question that needs to be asked is how an environment can be created that enables the student to engage and grapple with economics so that subject becomes of value and interest.

The traditional examination of the problem lies with the analysis of factors that could influence their performance. In this vain, some of these factors as were identified by Parker (2006) using the educational production function who found that:

- $\quad$ race had no effect;

- $\quad$ verbal and mathematical ability had significant positive effects on student achievement;

- $\quad$ student motivation, which was proxy by students devoting more or less time to formal classes. Those students who devoted more time achieved better results.

What this paper seeks to examine is not only factors relating to the student alone, but at the mode through which learning is facilitated in economics. So if you think of university economics you will probably visualise lecture theatres, textbooks, lecture notes, lectures, exercises, tutorials, exams and supplementary exams. No one has asked if this method is the best practice to facilitate learning and today, the educational content is still typically transmitted through "chalk-and-talk" sessions - the only difference being that delivery, now, is through the mediums of data projectors and PowerPoint presentations.

This view is supported by a study undertaken by Becker and Watts (2001) which compared surveys of academic economists in the United States during 1995 and 2000. They found there was an increased emphasis and interest in teaching, but that there had been no change in teaching methods which were still "chalk-and-talk" 
classroom presentations. The average time spent lecturing in all courses is still $83 \%$. Time devoted to the use of chalkboard for text writing and graphs during class is estimated at $83 \%$.

Becker and Watts (2001) further point out that the refusal to change the lecturing to alternative teaching methods reflects a situation where teaching efficiency outweighs the achievement of quality learning. The equilibrium is maintained by lecturers and students. "Students prefer teaching that enables them to listen passively... that organizes the subject matter easily for them and prepares them well for tests... research, however, points to better retention, thinking and motivational effects when students are more actively involved in talking, writing and doing... Thus, some teachers get high rating for teaching in less than ideal ways" (McKeachie, 1997, p.1218).

All the above factors, which contribute to the poor performance that is currently being experienced, may diminish in the long-run and a sustainable demand for economics as a major across disciplines may be created.

The purpose of introducing the concept of gaming into the method of tuition is that it has tangible benefits for both second- and first-language (Tompkins,1998; Mason and Fabritius,2000) students in securing the mastery of the subject. The benefits of using gaming increase motivation and students' engagement in the learning process.

The objectives of this article are to:

- $\quad$ educate curriculum developers and lecturers about the education value of games so that games become a common part of the formal academic tuition programme;

- $\quad$ encourage more active participation of students in the learning process through the use of games;

- $\quad$ show that games already exist for economics (micro- and macro-) that are freely available, and accessible e.g. Classroom Expernomics (http://www.marietta.edu/ delemeeg/expernom.html )

Leading academic institutions are already employing gaming as part of the accepted method of tuition. For example at MIT (USA) gaming forms part of the academic learning in subjects ranging from political science to physics. In 2002, a "Games-to-teach Project" was initiated which was a collaborative venture between MIT Comparative Media Studies and the Microsoft Corporation (http://cms.mit.edu/games/education).

The use of educational gaming in economics could be the key to "the longstanding goal in education of how to promote situations where a person is motivated to learn, is engaged in the learning act, is willing to go to great lengths to ensure learning will occur, and at the same time finds the learning process (not just the outcomes) to be satisfying and rewarding" (Rieber et al, 1998, p.5). If this type of learning could be achieved then the motivation to study economics could become sustainable and lead to the need for more economics majors.

\section{VALIDITY OF USING GAMES IN EDUCATION}

The method through which the delivery of education takes place is informed by the manner in which one views the concept of learning. If it is merely the accumulation of facts and skills, then the current status quo of lectures, textbooks and examinations will be deemed to be sufficient. In this concept of learning, "students come to think of knowledge as a packet of content waiting to be transmitted" (Venter, 2001, p.89). The lecture becomes the delivery vehicle of factual subject knowledge to the students. This minimalist learning environment encourages passive and rote learning, leaving little room for problem-solving or exploration of facts (Wilson,1995).

Reimann (2004), in reviewing first-year teaching-learning environments in economics at three different Universities in the UK, found a pattern similar to that of minimalist learning environments. These were characterised by:

- $\quad$ A neoclassical approach to economics;

- A uniform lecture-tutorial approach which emphasises passive learning;

- $\quad$ Content-driven, fast-paced lectures;

- $\quad$ Complemented by textbooks and tutorial worksheets.

2 
Under this system of learning "we are forced to learn by rote that is in no way connected to anything important in our lives..... being alien to our own life experiences outside the academic setting, they slip easily off our shoulders.........and vanish" (Gruender,1996, p.21). This may explain why many lecturers complain that students do not retain knowledge from one year of study to the next or even from one semester to the next. It may also explain to some degree the problems of plagiarism amongst students as rote learning is simply the restatement of fact as indicated by the lecturer or the text. So what would be wrong in providing an answer word-for-word if it is correct?

In order to change the method of teaching delivery, we need to review our ideas about learning and move beyond the behaviourist paradigm. In this process of re-examining our idea of learning, we will focus on the neuroscientific approach to learning through brain-based learning theories.

\section{THE BRAIN AND THE LEARNING PROCESS}

The brain and learning process cannot be separated - we learn with our brains. These insights are a result of neurological research into the manner in which the brain naturally learns which has resulted in the development of brain-based learning.

In accordance with the discoveries of how the brain learns suggestions have been made on the manner in which classroom practices can be modified. Caine and Caine (1990) provide a summary of recent research suggestions and the possible teaching implications.

Firstly, the brain performs many functions simultaneously and learning is therefore enhanced by a variety of stimuli (Ibid, 1990). The teaching suggestion is that a variety of teaching strategies be used which range from individual learning times and group interactions, to physical variations, to develop a student's learning experience.

Jensen (2000) compliments this notion that a rich, complex and multi-sensory environment encourages the brain to learn. Roberts (2002) suggests that the teacher becomes an orchestrator of learning environments rather than an instructor. That learning environments, therefore, need to employ multi-modal instruction techniques (visual, auditory, kinaesthetic) and multiple intelligence activities (Gardner, 1985). The introduction of simulations, roleplay into learning environments and the components of challenge, novelty, choice, feedback, social interaction and active participation would further encourage learning.

Caine and Caine's (1990) second insight is that the search for meaning is innate. The mind's natural curiosity can be engaged by complex and meaningful challenges. Educators should therefore strive to present lessons and activities that arouse the mind's search for meaning.

Roberts (2002) supports the notion that the brain is designed to search and integrate new information into meaningful patterns. If the information is meaningless then the brain actively resists. Hill (2001) suggests that our brains sort information according to whether it is associated with content or context.

Content information that is driven by rote learning, which is not brain compatible, requires continuous effort to retain knowledge. Context-learning, however, seems more effortless.

Willis (2006) suggests the metaphor of "educators as memory enhancers, not just information dispensers" (Ibid, 2006, p. 24). Through research Willis shows that learning without meaning is stored in the short-term memory and in the remote areas of the brain which makes it difficult to locate and for the information to be retrieved. Learning, on the other hand, that has meaning is stored in the long-term memory and is more easily retrieved.

Emotions and cognition are highlighted by Caine and Caine (1990) as crucial to the storage and recall of information, therefore, the learning environment should promote positive attitudes among teachers and students. Furthermore, students should be aware of their feelings and how emotions affect their work.

According to Hill (2001) emotions are vital to thought and learning i.e. the body, emotions, brain and mind are an integrated system and emotions are enmeshed in the neural networks. Emotions also play an important part in 
the encoding and retrieval of memory, and this can have both positive and negative effects on learning. On the one hand, meaningful and relevant information tends to be learned and remembered. In contrast emotional reactions such as depression, anxiety and stress can have a negative impact on learning and retrieval.

The implication is that learning environments need to take cognisance of the emotions so as to create motivationally challenging situations rather than those which cause uncertainty and anxiety.

In summary, Engel et al (2006) states "the healthy brain is, however, anything but a passive receiver of news from the environment. It is an active system, one that controls itself via a complex internal dynamic. Our experiences, intentions, expectations and needs affect this dynamic and thus determine how we perceive and interpret our environment" (Ibid, 2006, p.2). The brain, therefore, cannot be compared to a computer but rather more like a jungle ecosystem (Sylwester, 1993).This means that learning environments have to change to encourage learners to actively acquire meaningful information and in turn be motivated to learn.

This drive to create a new model of learning, through meaningful activity led Gee et al and Shaffer (2005) to the promotion of Epistemic Games as a solution. In these games, which are not just about knowledge but knowledge in action, players learn to work and think as innovative professionals.

In the teaching of concepts from books where the content is the focus, little attempt is made to develop per formative knowledge - "We don't think concepts, we think with concepts" (Pottier et al, 2003, p.37) - hence our students acquire facts but, have developed limited skills to think and reason.

Ellington (1998) captured the need for learners to be able to adapt their knowledge to diverse experiences in the following quote: "We live in a complicated and messy world in which work for most of our graduates is a continuous stream of 'problems' that have no simple or unique solutions" (Ibid, 1998, p.1). Therefore, our students need to think creatively to solve problems and this can only occur in active learning environments which could be created by utilising games and simulations.

This is supported by Amory and Seagram (2003) who suggest that games can provide a learning environment which:

- $\quad$ affects cognitive functions and motivations;

- $\quad$ stimulates curiosity through challenges;

- $\quad$ provides novelty and complexity;

- $\quad$ promotes goal formation and competition;

- $\quad$ all learners to be active; and

- $\quad$ intrinsically motivates learners.

Games provide an ideal educational opportunity to engage students actively thereby enhancing the learning process at academic institutions and their reintroduction into formal tuition is built on sound educational principles. The Game Achievement Model developed by Amory and Seagram (2003) aims at designing educational games that simultaneously challenge learners to actively participate in the learning process while achieving particular educational outcomes.

Therefore, part of the diversification process to enhance the learning process could be found by introducing educational games into formal learning time.

\section{STUDENTS' PERCEPTIONS AND PERFORMANCE}

My investigation looked at first year accounting students who were split into different career streams, namely, that of Cost and Management Accounting (CMA), Financial Accounting (FA) and Auditing at the Durban University of Technology in 2008. It is a course requirement for each of the participating groups to complete first year economics. All the groups were lectured by myself, which on the one hand ensured that differing lecturing styles from other lectures would not be a factor influencing the outcome, but on the other could provide potential 
bias later when answering the questionnaire on the game.

The planned approach for collecting the data followed an experimental path with control and treatment groups to evaluate the efficacy of the use of gaming as a teaching strategy. This efficacy was measured by obtaining the students' perspectives through surveys of the groups experiencing the game and the comparative performance of these students with other groups. This process of data collection had to plan for redundancy because of the possibility of events occurring that could not be controlled.

The experimental and redundancy plan was the following:

1. The control group comprised the Auditing students who received nothing but the traditional lectures. Their performance on test questions relating to law of diminishing returns was to be recorded.

2. Treatment Group 1 - Financial Accounting. This group was to receive the game, the quiz on the law of diminishing returns and their performance on test questions relating to the law of diminishing returns was to be recorded.

3. Treatment Group 2 - Cost and Management. This group was to receive the quiz on the law of diminishing returns and their performance on the test questions relating to the law of diminishing returns was to be recorded.

The redundancy plan comprised two possible measures for comparing the students' performance - (i) through a comparison between the performance on the quiz between Financial Accounting and the Cost and Management group; (ii) by comparing the performance of the three groups on the test questions.

While collecting the data the importance of having an alternative came to the fore, as on the day the quiz was run, students from the Financial Accounting group, who had played the game, were not present in sufficient numbers to make a valid comparison with the Cost and Management group. The diminishing returns questions in the test then became the measure as to whether the students performed better due to the game or the quiz, both or neither. As the Financial Accounting group was chosen to receive the game relating to the law of diminishing returns, they were surveyed with a questionnaire to capture their perceptions of this teaching intervention.

In addition to information gathered from the questionnaire and test performance results, generic information relating to English and mathematics grades, gender, as well as whether students were first- or secondlanguage speakers was also obtained, with institutional permission, in order to do statistical analysis to determine what factors could have influenced the outcomes of the test other than the quiz and the game.

\section{THE GAME}

The game that was used was based on one designed by Neral (1993) who, like me, identified that for many students the treatment of production and costs in the standard lecture and textbook mode is an endless maze of definitions and formulas that seem remote and difficult to relate to real world of production. His 'Classroom Widget Production' exercise proved helpful in bridging the gap between theory and experience, especially the law of diminishing returns.

\section{QUESTIONNAIRE}

A survey was conducted on the Financial Accounting students who had experienced the game. The questionnaire required demographic information from the students as well as Likert Scale and opened-ended questions to measure their perceptions towards this intervention being used as a teaching method.

The design and structure of the questionnaire was based on Klassen and Drummond's (2000) to measure the effectiveness of a business simulation on learning. This provided categories of questions aimed at eliciting information from students such as: 
1. Your Learning - To what extent did the multimedia package assist your learning in terms of knowledge, understanding, practice, feedback, correction and content?

2. The Instruction - How well did the multimedia package sequence activities, challenge your thinking, encourage problem solving, arouse interest, encourage you to work with others, fit your course?

3. Affective (feelings) - From your experience, did you feel the package to be stimulating, motivating and satisfying?

4. Technical - How would you rate the actual multimedia package, in terms of presentation, ease of use, problems, navigation?

5. General - Overall what is your opinion about, using this program again, recommending it to your fellow students, the organisation of "laboratory" experience, how worthwhile was the activity? (Ibid, 2000, p.13-15)

This proved to be a useful guide and basis when designing questions that would effectively measure the students' perceptions of the game concerning the law of diminishing returns. In addition, the questionnaire was examined and changes made according to input from colleagues in the Economics Department, as well as my supervisor, to ensure that it was an accurate measure of the students' perceptions.

\section{ANALYSIS OF THE QUESTIONNAIRE}

The questionnaire was completed by 56 Financial Accounting students with demographic questions related to language spoken, gender, studying economics for the first time or repeating economics and the nature of the funding of the studies. (Refer Table 1 below)

Table 1: A percentage breakdown of the demographics.

\begin{tabular}{|l|c|c|}
\hline \multicolumn{1}{|c|}{ Demographic Category } & Frequency & Percentage \\
\hline Language: & & \\
Zulu & 45 & 80.4 \\
English & 10 & 17.9 \\
Other & 1 & 1.8 \\
\hline Gender: & & \\
& 22 & 39.3 \\
Male & 34 & 60.7 \\
Female & & \\
Studying Microeconomics: & 50 & 89.3 \\
First Time & 6 & 10.7 \\
Repeating & & \\
\hline Financed by: & 34 & 60.7 \\
Parents/Family & 16 & 28.6 \\
Financial Aid/Loan & 4 & 7.1 \\
Bursary/ Scholarship & 1 & 1.8 \\
Parents and Bursary & & \\
\hline
\end{tabular}

With respect to language, $80.4 \%$ of the students were Zulu-speakers which meant this sample was dominated by second-language speakers with $10 \%$ as first-language speakers. The dominance, which is common in the DUT institution, may provide insight as to whether games can assist second-language speakers in acquiring knowledge in a first-language teaching and learning context.

The gender breakdown of the sample was $39.3 \%$ males and $60.7 \%$ female. This correlates as female students predominate in the accounting disciplines at DUT, which means that the introduction of games could be of benefit in introducing learning environments which are of benefit to both genders. 
$89.3 \%$ of the students were studying the subject for the first time with only $10.7 \%$ repeating the subject from the sample group. The dominance of first year students means that the sample will represent the perceptions of first year students.

$60.7 \%$ of the students in the sample were financed by parents and family while $28.6 \%$ were financed by financial aid or a loan. The rationale behind looking at the financing of students was an attempt to get an idea of the income level without having to ask directly about the economic pressure to succeed. In general, we could assume that those with loans came from lower income brackets as compared to those who were able to pay.

The Likert Scale questions were designed to capture the students' perceptions of the game as a medium of instruction. As these scales are ordinal (and not interval ratio) only the mode was used when looking at the descriptive statistics.

For the questions Q6 to Q18, the modes were the following:

Table 2: Student's perceptions of the game

\begin{tabular}{|l|c|}
\hline \multicolumn{1}{|c|}{ Questions } & Overall Mode \\
\hline Q6. The game increased my knowledge & 4 \\
\hline Q7. The game improved my overall understanding of the concepts of Diminishing Returns & 4 \\
\hline Q8. The game enabled me to apply the theory in a typical situation & 4 \\
\hline Q9. The game was clearly organised & 4 \\
\hline Q10. The game challenged my thinking about Diminishing Returns & 4 \\
\hline Q11. The game encouraged problem solving & 4 \\
\hline Q12. The game made Diminishing Returns more interesting to me & 4 \\
\hline Q13. Working with other students was helpful in developing understanding of Diminishing Returns & 5 \\
\hline Q14. The game stimulated my interest in economics & 4 \\
\hline Q15. Working with others was enjoyable & 5 \\
\hline Q16. I would recommend using this game to teach Diminishing Returns in lectures next year & 5 \\
\hline Q17. I would recommend this game to fellow students to help revise the theory of Diminishing Returns & 5 \\
\hline Q18. Overall I found the experience of the game to be worthwhile & 4 \\
\hline
\end{tabular}

These findings were confirmed by the frequency tables

\section{Mode code}

1 - Completely disagree; 2 - Disagree; 3 - Unsure; 4 - Agree; 5 - Completely Agree

One could therefore deduce that the use of the game was worthwhile in assisting the students to learn about the law of diminishing returns.

The purpose of the open-ended questions (Q19 to Q22) was to get students to express, in their own words, what they experienced or learned.

On the whole the answers to Q19 indicated that the game assisted their learning in one area or another while Q 20 revealed most of the students felt it was of benefit to work in groups and 'that it helped develop their knowledge.

Q21 dealt with their dislikes of this method of teaching. Here the organisation of the game and the behaviour of other students predominated.

Overall, the open-ended questions showed that most benefited from the game as a learning experience, but that the game needed better organisation and more explicit outcomes to add more value to the learning experience. 
The data from the Likert Scale questions was then compared with the demographic factors to see whether there was any difference in variance. The Mann-Whitney U test was used to test for possible correlations because the dependant variables (Likert Scale questions) are ordinal instead of interval or ratio and the data was reduced to two levels.

No significant results were found between those studying economics for the first time or repeats or according to financing of studies. However, there was a significant difference for language and gender.

Language was reduced to two categories, namely, Zulu and English for the purpose of analysis as the frequency of other languages was only 1. This occurred for Q14 and Q15 only. In order gain some idea of the possible reasons I looked at cross tabulations for these against Q14 and Q15.

For Question 14, 59.1\% of Zulu speakers and only $20 \%$ of English speakers agreed that it stimulated their interest in economics.

For Question 15, 61.4\% of Zulu speakers completely agreed that working with others was enjoyable whereas $40 \%$ of the English speakers were unsure.

The reasons for this could be that Zulu speakers come from a cultural background which is more communal and where group interaction is more common. Whereas English speakers come from a more individualistic society, where group interaction especially in educational setting, is not the norm. Brock-Utne (2002) state that the African education system could be described as a system of linkages:

- $\quad$ "Linkage between general knowledge and practical life - transmission of knowledge through practical exercises;

- $\quad$ Education was linked to production;

- $\quad$ Education was linked to social life;

- $\quad$ Education was linked to culture through the use of mother tongue;

- $\quad$ Education was linked to culture through the incorporation of cultural practices like games, dancing, music and sports;

- Education was linked to ethical values" (Ibid 2002, p.238)

So learning through written academic texts with no relation to society may disadvantage African students. This may explain why the Zulu speakers have a more positive response to the game as being part of the learning process.

Table 3: Gender significance

\begin{tabular}{|l|c|c|}
\hline \multicolumn{1}{|c|}{ Question } & Gender & Response \\
\hline $\begin{array}{l}\text { Q8. The game enabled me to apply } \\
\text { the theory in a typical situation }\end{array}$ & $\begin{array}{l}\text { Male (36.4\%); Female (22.6\%) } \\
\text { Male (40.9\%); Female (54.8\%) }\end{array}$ & Completely Agreed \\
\hline $\begin{array}{l}\text { Q12. The game made Diminishing } \\
\text { Returns more interesting to me }\end{array}$ & Male (23.8\%); Female (47.1\%) \\
\hline $\begin{array}{l}\text { Q17. I would recommend this game } \\
\text { to fellow students to help revise the } \\
\text { theory of Diminishing Returns }\end{array}$ & Male (52.4\%) & Agreed \\
\hline $\begin{array}{l}\text { Q18. Overall I found the experience } \\
\text { of the game to be worthwhile }\end{array}$ & Female (58.8\%) & Strongly Agreed \\
\hline
\end{tabular}

The gender differences for questions 12,17 and 18 seemed to reflect that females were more certain than their male counterparts that the game made the law of diminishing returns interesting; that they would recommend it to fellow students; and that the experience was worthwhile. 
Question 8, indicates that perhaps, for males, playing the game in a more realistic setting would have made them agree that they would be able to apply the theory in a typical situation whereas for the female students the setting did not seem to affect their responses.

The game here seemed to provide a situation where gender differences could be incorporated so that the learning could occur without bias to one gender or another.

\section{PERFORMANCE OF STUDENTS IN RELATED QUESTIONS}

The students' performance was measured from their second summative assessment - a multiple choice test which included three questions that related to the law of diminishing returns directly (10\% of the paper). Two occurred concurrently and the third towards the end of the test.

The performance over these three multiple choice questions was then compared to see if there was significant variance between the mean performances of the three groups.

One-way ANOVA in SPSS 15 was used. The mean differences in performance between the groups, was significant but in order to provide more analysis the following post hoc tests were undertaken:

1. Tukey HSD - variances in the population were assumed to be equal (Field 2008).

2. Games-Howell - variances in the population are not equal and also if the group sizes are unequal (Field 2008, Newsom 2008).

3. Dunnett $\mathrm{t}$ (2-sided) - used to test the variances between the control group and treatment groups (Field 2008).

According to all three post hoc tests there was only a significant difference between the Auditing and the Financial groups (Ibid). This would indicate the difference in the performance between the two could be attributed to the teaching intervention of the game.

In looking at learning we know that it is complex by nature and in order to add more value to the findings an ordinal regression was done, for two key reasons:

1. Firstly, to see if factors other than the game could have influenced the results as learning is a result of complex interactions;

2. Secondly because the factors are easily measured i.e. not interval or ratio data but rather nominal or ordinal, thus making us look for non-linear regression.

Ordinal Regression is based on probability theory. In order to do this the marks were ranked according to their values and compared to a set of variables which were accessed from generic data from the DUT institution. In addition they were based on a paper by Parker (2006) on the effect of student characteristics on performance on introductory microeconomics across five South African Universities which found that gender, whether a student was first- or second-language speakers, verbal and mathematical ability affected his/her performance. Added to these factors were whether the students did the game or not and the quiz.

As mathematics and English points were continuous variables (covariates) in the model for the ordinal regression, one could expect a warning that there would be cells with counts $>5$ or $=0$, which could be ignored.

According to the ordinal regression ${ }^{1}$ model the factors of English ability, gender and whether the students were first- or second-language speakers were found not to be significant. However, mathematics points, for those having done the game and quiz were significant.

\footnotetext{
${ }^{1}$ The ordinal regression model fits as the level of significance is 0.001 which less than 0.05 ; has a goodness of fit of 0.507 which is acceptable and the Test of Parallel lines was 0.239 which means that there is no violation of the proportional odds assumption.
} 
Plum Ordinal Regression: Parameter Estimates

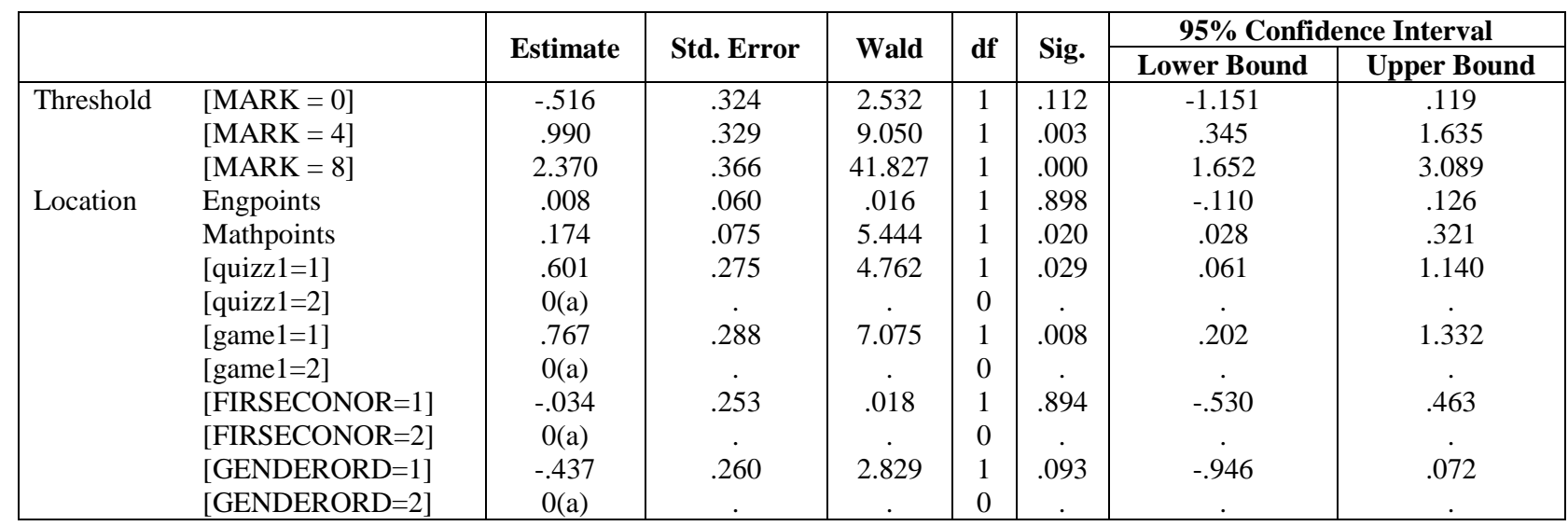

Link function: Logit.

a This parameter is set to zero because it is redundant.

With respect to the ordinal regression, for every increase in one maths point log odds increased by 0.174 as one moved to a higher mark category. By participating in the game the log odds improved by 0.767 ; and if the quiz was completed the improvement was 0.601 .

The result of the ordinal regression that mathematics ability, playing the game or quiz had a significant impact on performance was not unexpected for the following reasons:

1. Microeconomics is highly mathematically dependent in terms of being able to calculate values, plot values and interpret outcomes.

2. The shortage of mathematics teachers and poor performance in Matriculation mathematics in South Africa could add to the importance of maths as a subject.

3. Weak mathematics skills also affect the time spent by students in focusing on the mechanics of calculating and not the interpretation of the values. Thus perhaps there is a need for maths literacy as there is for English - even though you know the grammatical rules it does not mean you can write a coherent argument.

4. The finding that gaming had a significant effect was inline with expectations from literature that indicates that gaming provides a vehicle for long-term deep learning.

5. The fact that the quiz had an impact was also not unexpected as indicated by van der Merwe (2006) and Parker (2006) that practice in doing economics increases performance. Thus often one has the introduction of workbooks, computer-aided learning, and tutorials.

\section{CONCLUSIONS AND RECOMMENDATIONS}

The results from the questionnaire of the students' perceptions towards the game being used as method of teaching in economics was very similar to the literature reviewed (Motahar, 1994; Gremmen and Potters, 1997; Meister, 1999; Mason and Fabritus, 2000; Woltjier 2005). This concluded that students responded positively to this teaching intervention and believed it assisted their learning. The majority of the students stated that the game: "emphasizes the theory in a practical way that made it easier to understand / an easy way to understand the law of diminishing returns".

The recommendation from the students' perspective is that the use of games should be used more as a teaching method. The scope of the introduction of gaming, therefore, needs to be expanded into other economic topics within the curriculum as well as other areas. This view was expressed by the following quote from Question 22: "It should be done more often - not only for the law of diminishing returns". 
As for proving that these student perceptions translated into increased performance, the study was limited in that it could only make a comparison between the control group and the treatment groups of three multiple choice questions relating to the law of diminishing returns. It did, however, provide some useful insights into the factors that could have affected their performance.

From the results of the ordinal regression from, we were able to work out the $\exp (b)$ for each of the factors, according to the odds ratio in order to get a clear picture of the ranking of the most significant factors which were maths points, the game and the quiz:

1. For each maths point the odds ratio $\exp (0.174)=1.12$. This means that if a candidate had four maths points, he/she had a 4.48 times probability of performing better.

2. For having experienced and done the game the odds ratio $\exp (0.767)=2.17$. This indicated that the candidate had a 2.17 times probability of performing better.

3. For having experienced and done the quiz the odds ratio $\exp (0.601)=1.82$. This indicated the candidate had a 1.82 times probability of performing better.

Maths became an important factor in determining the probability of their success in the questions relating to the law of diminishing returns. This highlights the mathematical nature of current microeconomics courses where it is not only the ability to work out equations and draw graphs but, also to interpret the results and apply it to the outcomes.

This maths ability or competence of being able to apply the findings is critical. For example in the law of diminishing returns you need to workout the marginal and average products from the total product as well as identify when the law of diminishing returns starts for the marginal, average and total product.

The mechanics of maths will get you the values, but the competence in maths will give you the ability to identify where and what the law of diminishing returns represents.

At DUT the maths competence of the students is weak and the capacity to do the mechanics fair. This is where the game tended to assist students as they were placed within a more relaxed environment for the explanation of the law of diminishing returns. They saw the law at work for themselves in a practical environment and began to understand what is meant by the word 'diminishing' i.e. a decrease in the rate of increase of the level of production whether at the total, average or marginal levels of production. This is illustrated by a student's comment that: "It helped because visually we could see it happen rather than reading in a text book".

Perhaps this method of teaching is what gave the students a better probability of performing better over the three questions than those who did not - as the game helped students develop their mathematical competence, as well as the mechanics.

In addition, it has been shown from literature (Huyen and Nga, 2003;Kennedy 2006) that gaming assists second-language speakers in learning and language competence. This potential of games needs to be exploited to in order to improve the quality and performance of our students who are in the majority second-language speakers.

The effect of the quiz also positively affected the performance of students, this could be attributed to the fact that the quiz allows students to practice what they have learned on their own. Van der Merwe (2006) noted that students favoured the introduction of a workbook to give them an opportunity to practice economics which they felt would increase their performance in the subject.

Perhaps, we need to provide room for both games and quizzes in order to create a better learning fit for students i.e. used to both reinforce learning gains from gaming and that of practicing knowledge. This may involve the use of a workbook with questions relating to the concepts tested in the game or computer-added learning where students can go on-line, for example with web-ct, and practice what they have learned. 
The overall recommendation is that there needs to be an integrated approach where the learning environment needs to be blended with gaming, lecturing and practice so that the quality and performance of students can be improved.

In addition, the role of gaming needs to move from a diversion exercise and as introducing to concepts to being central to the learning and teaching process to achieve learning outcomes and can even be developed to provide a method of testing these concepts (Pratt, 2004).

Games have already been developed which address various economic topics from simulations to classroom experiments. One merely needs to Google the topic and search for an appropriate game which then needs to be modified to one's own particular set of circumstances. In my case I found the following website useful with respect to Classroom Expernomics: http://www.marietta.edu/ delemeeg/expernom.html

\section{THE WAY FORWARD}

There are many benefits for introducing gaming into the formal lecturing programme. Ellington (1998) provides a brief summary of the main educational strengths of games, namely, that they:

- $\quad$ provide a highly versatile and flexible medium through which a wide variety of educational outcomes can be achieved;

- $\quad$ be tailor-made to meet the learners' needs;

- $\quad$ achieve positive transfer of learning and encourage deep learning (Entwhistle 1996);

- $\quad$ use and develop learners' initiative and creative powers of thought;

- $\quad$ help foster a wide variety of skills such as decision-making, communication and interpersonal;

- help develop attitudinal traits such as willingness to accept others' points of view or appreciate that most problems can be solved in a number of ways;

- $\quad$ provide strong motivation for learners to willingly engage in learning.

(Ibid, p. 10-11)

Ellington (1998) also highlighted some of the weaknesses of games which are:

- $\quad$ organisational problems which involve fitting them into them into normal teaching time and curriculum; large classes and extra teaching staff etc.;

- $\quad$ they require active cooperation of learners;

- $\quad$ using games for wrong reasons such as a diversions or time fillers;

- $\quad$ the game educational outcomes must be matched to the target population.

(Ibid, p.11-12)

From Ellington's arguments the reasons for using gaming as a form of teaching in a formal education setting has merit and most of the weaknesses seem to be natural problems when encountered while designing a learning curriculum especially that of matching educational outcomes with current educational practice.

In addition, from the study we learned that most of the students gave their active cooperation to the game willingly and enjoyed the learning experience. So under clear and confident presentation of the game, students will actively engage with the game.

But, the fitting in of games into formal learning programmes as they are currently pursued tends to exclude their use to their fullest potential due to time constraints, structure of lecture venues and resources. This becomes an area for future research not only for my own discipline, but also across other disciplines.

In addition to this, games will create a labour force that can compete in a global world. With the advent of globalisation Gee and Shaffer (2005) point out that not only manufacturing jobs are under threat, but even those of professionals as they can all be produced more cheaply and more efficiently outside of one's country. 
The only factor that will ensure employment is the ability of human capital to be innovative. To achieve this, the labour force needs to be empowered to become independent thinkers and make appropriate judgements with the information they can access (Huang, 2006).

The current situation, according to Gee and Shaffer, is a result of the current formal education system that encourages rote learning and which cannot produce innovative thinkers. Epistemic games, however, let players learn to work and think as innovative professionals. It is not just about knowledge but knowledge in action which involves making, applying and sharing.

If we were to create an education system that produced this type of human capital it could provide learners with the ability to become entrepreneurs who could innovatively put South African factors of production together in new forms to produce more diverse products that could help alleviate unemployment and poverty in the country. would be:

As for further research on the topic of challenges for games and simulations for learning, the two key areas

1. Role of games and simulations in learning - This would include looking at games in terms of being adapted for particular audiences i.e. primary, secondary, tertiary and adult learners. How curricula could be designed to exploit the effectiveness of gaming; and

2. Understanding change in education and training institutions - investigate why the adoption of gaming is so slow.

The use of games as a valid form of instruction and even testing of learning is well established through literature and educational theory. The avoidance of using this method for teaching economics and other disciplines with my institution and across the country of South Africa seems at best non-existent or hidden from plain sight. With the pressures of dealing with large numbers, second-language speakers and students with weak mathematical ability, the proof exists that gaming can help address these problems faced by educators.

Yet the reluctance for institutions, administration, lecturers and curriculum developers to incorporate this into the formal tuition programme is not rational. If we carry on with this type of approach we will fall behind the rest of the world in producing human capital that is innovative and creative ensuring that we will become a third world nation forever relying on foreign business expertise to develop our economy and never exploiting the indigenous diversity of our human capital.

\section{AUTHOR INFORMATION}

Jason Stratton Davis, is currently a lecturer in the Department of Public Management and Economics at the Durban University of Technology which is located in Durban South Africa. I lecture Economics to mainly first year students and have a keen interest economic teaching and learning. Apart from my research economic education, I have research interests in Development and Transportation Economics.

\section{REFERENCES}

1. Amory, A., \& Seagram, R. (2003). Educational Game Models: Conceptualisation and Evaluation. South African Journal of Higher Education, 17(2).

2. Becker, W. E., \& Watts, M. (2001). Teaching methods in U.S. undergraduate economics courses. Journal of Economic Education, 32 (3) Summer.

3. Brock-Utne, B. (2002). Stories of the Hunt - Who is writing them? The importance of indigenous research in Africa based on local experience. In C. A. Odara Hoppers (Ed.), Indigenous Knowledge and Integration of Knowledge Systems: Towards a Philosophy of Articulation. Cape Town: New Africa Books.

4. Caine, G., \& Caine, R.N. (1990). Understanding A Brain Based Approach to Learning and Teaching. Educational Leadership, 48 (2), 66 - 70 (Excerpts).

5. Davis, J. (2009). Students' perceptions of gaming as part of a first year economics' topic. Unpublished Submitted as a requirement for fulfillment of Master's Degree at the University of KwaZulu-Natal. 
6. Ellington, H., \& Earl, S. (1998). Using Games, Simulations and Interactive Case Studies - a practical guide for tertiary-level teachers. Paper presented at the SEDA Paper 101.

7. Engel, A. K., Debener, S., \& Kranczioch, C. (2006). How the brain decides what to focus conscious attention on (Publication. Retrieved 10 June 2007: http://www.sciamind.com/print_version.cfm?articleID=00001590-CDCC-14C7-8D...

8. Gardner, H. (1985). Frames of Mind: The theory of Multiple Intelligences. New York: Basic Books.

9. Gee, J. P., et al. (2005). Video Games and the future of Learning. Unpublished Working Paper. WCER.

10. Gremmen, H., \& Potters, J. (1997). Assessing the Efficacy of Gaming in Economic Education. Journal of Economic Education, 28(4).

11. Gruender, C. D. (1996). Constructivism and learning: A philosophical appraisal. Educational Technology, May - June 1996, 21 - 29.

12. Guerrien, B. (2002). Is There Anything Worth Keeping in Standard Microeconomics? (Publication. Retrieved 23 August 2005: http://www.paecon.net/PAEtexts/Guerrien.htm

13. Hill, L. H. (2001). The brain and consciousness: Sources of information for understanding adult learning. New Directions for Adult and Continuing Education, 8, 73 - 81.

14. Jensen, E. (2000). Brain-based Learning. San Diego, CA: The Brain Store.

15. Kennedy, T. J. (2006). Language Learning and Its Impact on the Brain: Connecting Language Learning with the Mind Through Content-Based Instruction. Foreign Language Annals, 39(3), 471 - 486.

16. Klassen, J., \& Drummond, D. (2000). Human resources skills: Learning through an interactive multimedia business simulation International. Journal of Educational Technology, 2(1).

17. Mason, P. M., \& Fabritius, M. M. (2000). Using Student Data to Teach Utility Maximising Behaviour. Classroom Expernomics, 9.

18. McKeachie, W. J. (1997). Student ratings: the validity of their use. American Psychologist, 52(November), $1218-1225$.

19. Meister, J. P. (1999). Oligopoly -- an in-class economic game. Journal of Economic Education, 30(4).

20. Menlo, A., \& others. (1979). Teaching Educators of Adults How To Facilitate Participation in Adult Learning Groups. Unpublished paper. Ann Arbor, Mich: University of Michigan, School of Education.

21. MIT Comparative Media Studies., \& Microsoft. (2001). Games-to-Teach Project. from http://cms.mit.edu/games/education

22. Motahar, E. (1994). Teaching Modeling and Simulation in Economics: A Pleasant Surprise Journal of Economic Education, 25(4).

23. Neral, J. (1993). Widget Production in the Classroom. Classroom Expernomics, 2(1).

24. Parker, K. (2006). The Effect of Student Characteristics on Achievement in Introductory Microeconomics in South Africa. South African Journal of Economics, 74:1(March), 1 - 14.

25. Pottier, J. (2003). Negotiating Local Knowledge: An Introduction. In J. Pottier, P. Sillitoe \& A. Bicker (Eds.), Negotiating Local Knowledge: Identity and Power in Development (pp. 1 - 29). London: Pluto.

26. Pratt, G. (2004). Use of Simulations in Economics Instruction. from http://www.mdl.dist.maricopa.edu/mlx/slip.php?item=1389

27. Reimann, N. (2004). First-year Teaching-Learning Environments in Economics. International Review of Economics Education, 3(1), 9 - 38.

28. Roberts, J. W. (2002). Beyond learning by doing: The brain compatible approach. The Journal of Experiential Education, 25(2), 281 - 285.

29. Shaffer, D. W., \& Gee, J.P. (2005). Before Every Child is Left Behind: How Epistemic Games Can Solve the Coming Crisis in Education. In (Vol. 2005 - 7): Wisconsin Centre for Education Research.

30. Sylwester, R. (1993/4). What the Biology of the Brain Tells Us About Learning. Educational Leadership, 31(December / January), 46 - 51.

31. Tompkins, P. K. (1998). Role Playing/ simulation. The Internet TESL Journal, 4(8).

32. van der Merwe, A. (2006). Identifying Some Constraints in First Year Economics Teaching and Learning at a typical South African University of Technology. South African Journal of Economics, 74:1(March).

33. Venter, E. (2001). A constructivist approach to learning and teaching. South African Journal of Higher Education, 15(2), 86 - 92.

34. Vygotsky, L. (1978). In T. M.Cole (Ed.), Mind in Society. Cambridge, MA: Harvard University Press. 
35. Willis, J. (2006). An ASCD Study Guide for Research-Based Strategies to Ignite Student Learning (Publication., from ASCD:

http://www.ascd.org/portal/site/ascd/template.chapter/menuitem.b71d101a2f7c208cdeb3f...

36. Wilson, B. (1995). Metaphors for instruction: Why we talk about training environments? Educational Technology (September - October).

37. Woltjer, B. (2005). Decisions and Macroeconomics: Development and Implementation of a Simulation Game. Journal of Economic Education, 36(2). 


\section{NOTES}

